\title{
Successful thoracoscopic resection of large symptomatic mediastinal lymphatic malformations: Report of 3 cases
}

\author{
Amy W. Cheng, MD, Donald B. Shaul, MD, and Roman M. Sydorak, MD, MPH, Los Angeles, Calif
}

\footnotetext{
From the Department of Pediatric Surgery, Kaiser Permanente Los Angeles Medical Center, Los Angeles, Calif. Disclosures: Authors have nothing to disclose with regard to commercial support.

Received for publication April 8, 2015; revisions received June 11, 2015; accepted for publication July 4, 2015 available ahead of print July 31, 2015.

Address for reprints: Roman M. Sydorak, MD, MPH, Department of Surgery, Kaiser Permanente Los Angeles Medical Center, 4760 Sunset Blvd, 3rd Fl, Los Angeles, CA 90027 (E-mail: roman.m.sydorak@kp.org). J Thorac Cardiovasc Surg 2015;150:e59-60 $0022-5223 / \$ 36.00$

Copyright (C) 2015 by The American Association for Thoracic Surgery http://dx.doi.org/10.1016/j.jtcvs.2015.07.020
}

Lymphatic malformations (LMs) consist of masses of abnormal lymphatic channels. Their incidence is 1 in 5000. ${ }^{1}$ The majority of LMs occur in the head and neck, and malformations involving the mediastinum are uncommon. Complications and symptoms of mediastinal LMs are associated with their compressive mass effects and location. One of the mainstays of LM treatment is surgical resection. ${ }^{2}$ Lesions of the chest can be approached via the open or thoracoscopic approach. Although performed, there are very few articles describing the resection of these lesions via a minimally invasive approach. ${ }^{3}$ We report 3 cases of mediastinal LMs that were successfully resected via the thoracoscopic approach. Final pathology all showed LM.

\section{CLINICAL SUMMARY Patient 1}

A 2-year-old previously healthy girl presented with wheezing and fever. Chest radiograph noted a $3-\mathrm{cm}$ soft tissue density to the left of the mediastinum, with a cystic mass in the left neck extending in to the superior mediastinum. These were further visualized with computed tomography (Figure 1). The patient underwent thoracoscopic resection of the mass.

The operation was performed via four $3-\mathrm{mm}$ ports. A $3 \times 3 \times 3 \mathrm{~cm}$ left mediastinal thoracic mass was found in the upper thoracic cavity with extension through the thoracic inlet into the left neck. The mass completely

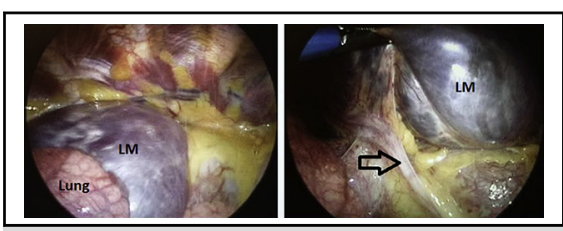

Large anterior mediastinal mass with extension into the right thoracic. The arrow points to the phrenic nerve.

\section{Central Message}

We report on 3 patients with symptomatic mediastinal LMs who underwent successful thoracoscopic resection.

See Editorial Commentary page e61.

encompassed the left brachiocephalic vein, subclavian vein, aortic arch, common carotid artery, right brachiocephalic artery, and vagus nerve. It was fluid-filled. The majority of the mass was resected with the hook cautery and LigaSure device (Covidien, Minneapolis, Minn) and a small percent of the wall of the tumor was left in the thoracic inlet. This was marsupialized into the chest. A thoracostomy tube was placed intraoperatively.

The patient was noted to have a left hydrothorax 2 months postoperation after presenting with a cough. Her symptoms resolved with drainage via a left tube thoracostomy. She was asymptomatic and doing well at follow-up 1.5 years later with a normal chest radiograph.

\section{Patient 2}

A 14-year-old girl with Klippel-Trenaunay-Weber syndrome presented with chest pain. Magnetic resonance
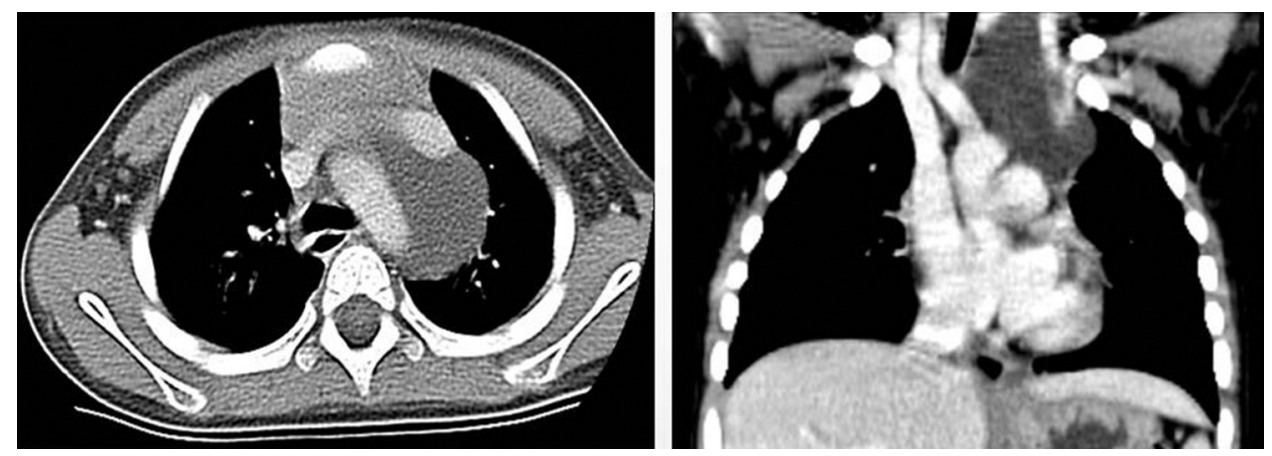

FIGURE 1. Computed tomography scan showing a $3-\mathrm{cm}$ soft tissue density to the left of the mediastinum, with a cystic mass in the left neck extending into the superior mediastinum. 

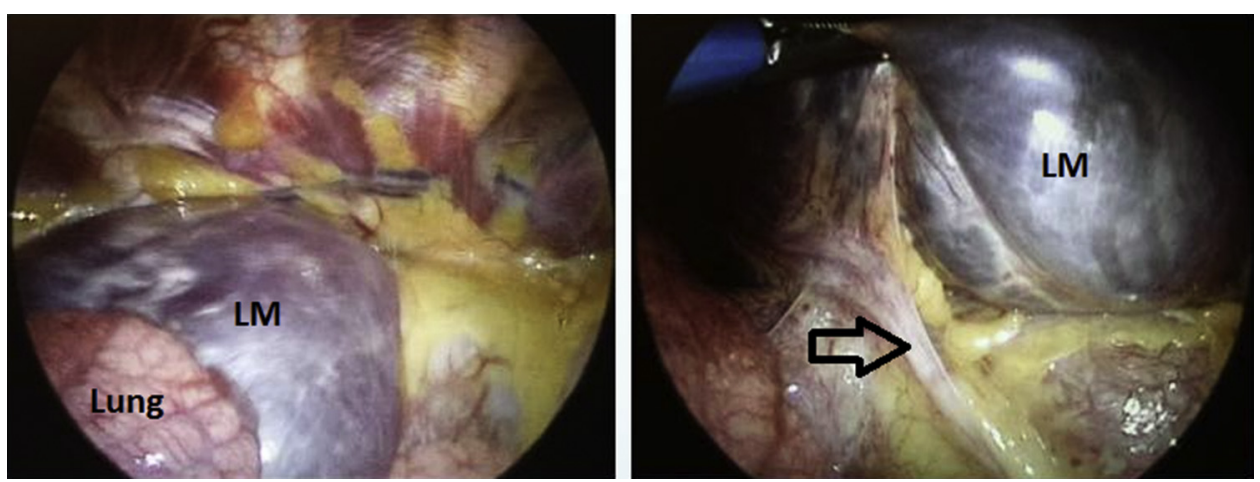

FIGURE 2. Large anterior mediastinal mass with extension into the right thoracic. The arrow points to the phrenic nerve. $L M$, Lymphatic malformation.

imaging and computed tomography scan showed a $9.6 \times 8.5 \times 4.4 \mathrm{~cm}$ lobulated mediastinal mass with potential encroachment on the right atrium and superior vena cava.

The patient underwent a right thoracoscopic resection of her mass via four 5-mm ports. One port was eventually upsized to a $12-\mathrm{mm}$ port for extraction. The anterior mediastinal mass extended into the right thoracic cavity and had a separate component along the aortoesophageal groove (Figure 2). The mediastinal mass was resected mostly intact. The anterior-most component in the aortoesophageal groove was dissected free. The thoracic duct was noted to be abnormally large and was oversewn at the level of the diaphragmatic hiatus. A tube thoracostomy was placed intraoperatively.

The patient had resolution of her symptoms postprocedure.

\section{Patient 3}

Our third patient was prenatally diagnosed via ultrasound with a large complex mass in the neck that extended intrathoracically. He underwent a planned ex utero intrapartum treatment procedure and was started on sclerotherapy with Sotradecol foam (Bioniche Pharma USA, Bogart, Ga) for his neck lesion. Repeat imaging showed increase in the size of the malformation with mass effect. The thoracic component of his LM prevented extubation.

He underwent bilateral thoracoscopic resection of his anterior mediastinal LM at age 1 month. Four $3-\mathrm{mm}$ ports were used on the right and 3 were used on the left. There was a $10 \times 8 \times 6 \mathrm{~cm}$ anterior mediastinal LM noted upon entering the chest and this was opened sharply and decompressed. A complete excision of the mass was performed. Bilateral tube thoracostomies were placed intraoperatively.
This patient's postoperative course was complicated by a left chylothorax that resolved with bedside tube thoracostomy and conservative management. He was started on sirolimus for his neck mass and continued on mechanical ventilation via a tracheostomy tube. He was discharged at age 2 months with sirolimus and on home ventilation. He was decannulated at age 1 year. He had tracheomalacia that improved with time. His vocal cords and phrenic nerve were normal.

\section{DISCUSSION}

Nonsurgical options for the treatment of LMs, including sclerosing agents, aspiration, carbon dioxide laser, and conservative management with observation, are widely used. ${ }^{4}$ Nevertheless, the multitude of treatment options also point to the general lack of consensus regarding the best therapy for this disease process.

We describe 3 cases of mediastinal LMs diagnosed in their various stages that were successfully resected thoracoscopically with minimal postoperative morbidity. Thoracoscopic resection of intrathoracic LMs can be feasible and reasonable for surgeons with advanced laparoscopic skills who are familiar with thoracoscopy and should be considered in pediatric populations.

\section{References}

1. Perkins JA, Manning SC, Tempero RM, Cunningham MJ, Edmonds JL Jr, Hoffer FA, et al. Lymphatic malformations: current cellular and clinical investigations. Otolaryngol Head Neck Surg. 2010;142:789-94.

2. Perkins JA, Manning SC, Tempero RM, Cunningham MJ, Edmonds JL Jr, Hoffer FA, et al. Lymphatic malformations: review of current treatment. Otolaryngol Head Neck Surg. 2010;142:795-803.

3. Komatsu T, Takahashi Y. Mediastinal cystic lymphangioma in a patient with situs inversus totalis. Case Rep Surg. 2014;2014:781874.

4. Sanlialp I, Karnak I, Tanyel FC, Senocak ME, Büyükpamukçu N. Sclerotherapy for lymphangioma in children. Int J Pediatr Otorhinolaryngol. 2003;67:795-800. 